\title{
Investigation of Heavy Organics Precipitation from Nigerian Crude Oil Residue Using Binary Mixture of n-Alkane Solvents
}

\section{${ }^{* 1}$ ANUCHI, SO; ${ }^{1}$ CHUKWU, UJ; ${ }^{1}$ OFODILE, SE}

\author{
Department of Pure and Industrial Chemistry, University of Port Harcourt, Nigeria \\ samson.anuchi@uniport.edu.ng
}

\begin{abstract}
The effects of mixing two n-alkane solvents on the precipitation of heavy organics in crude oil were carried out. The crude oil sample sourced from a major operative in Nigeria was distilled at $240^{\circ} \mathrm{C}$ and used for the precipitation experiment. The binary mixture of n-alkane solvents $\left(\mathrm{C}_{6}: \mathrm{C}_{10}, \mathrm{C}_{6}: \mathrm{C}_{16}, \mathrm{C}_{10}: \mathrm{C}_{14}, \mathrm{C}_{10}: \mathrm{C}_{16}, \mathrm{C}_{14}\right.$ : $\left.\mathrm{C}_{16}\right)$ was carried out in the solvent ratio of 0:1,1:2, 1:1, 2:1, and 1:0 respectively. From the results, $\mathrm{C}_{6}: \mathrm{C}_{10}$ mixture shows an abrupt decrease in heavy organics precipitated from 1:0 volume ratio of $\mathrm{C}_{6}$ : $\mathrm{C}_{10}$ to 2:1 volume ratio of $\mathrm{C}_{6}$ : $\mathrm{C}_{10}$ and a further steady decrease were observed. The percentage volume increment of $\mathrm{C} 6$ in the mixture of $\mathrm{C}_{6}: \mathrm{C}_{16}$, also shows steady and an abrupt decrease in heavy organics precipitated, which indicates phase transitions occurring at 1:1 and 2:1 volume ratio points. The additions of $\mathrm{C}_{10}$ to $\mathrm{C}_{14}$ and $\mathrm{C}_{10}$ to $\mathrm{C}_{16}$ results to decrease in the weight percentage of heavy organics precipitated. While a slight decrease in weight percentage of heavy organics occurs during the addition of $\mathrm{C}_{14}$ to $\mathrm{C}_{16}$. Precipitation experiment carried out using binary mixture shows a three-stage phase transition: solid-liquid, liquid-solid and solid-liquid in $\mathrm{C}_{6}$ : $\mathrm{C}_{16}$ at different volume ratios of the mixtures. (CJASEM

https://dx.doi.org/10.4314/jasem.v21i6.26
\end{abstract}

Keywords: Binary mixture, heavy organics, crude oil residue, n-alkane solvents, precipitates

The formation of heavy organics deposits during petroleum production can cause several technical issues including partial or total blockage of wellbores, pipelines, and damage to equipment (Salami et al. 2016). The heavy organics depositions in the oilfield have negative impacts to well economics due to the reduction in the production of crude oil and increase the cost of production and transportation (Escobedo; Mansoori 2010).

However, heavy organics (HOs) are heavy components of crude oil, which fractions include saturates, aromatics, resins, and asphaltenes with vary polarity and solubility (Mansoori et al. 2007). These compounds precipitate out from crude oil when changes in physical properties including temperature, pressure, and composition occur, which leads to deposition and blockage of wellbore and pipelines (Escobedo; Mansoori 2010).

To find a reliable solution to mitigate HOs deposition problems, several studies have been carried out to understand the mechanisms, nature, and behaviour of HOs deposition from crude oil. For example, several researchers have carried out the laboratory precipitation experiments of HOs from crude oil using individual n-alkanes solvents (Eduado et al. 2004; Mansoori et al. 2007; Chukwu et al. 2011; Tobrise et al. 2016; Anuchi; Chukwu 2017). However, the mechanism of deposition of heavy organics from crude oil in the oilfield can be better understood by precipitation of HOs from oil in the laboratory using binary mixtures n-alkane than only the individual solvents. This is because the binary precipitation experiment gives a closer insight into understanding the susceptibility of petroleum to HOs precipitation in the oilfield (Achugasim; Ekpo 2015).

Consequently, Udourioh et al. (2014) studied the precipitation of HOs from crude oil using binary mixtures of low molecular weights n-alkanes, which include n-pentane, n-hexane, and n-heptane. While Achugasim; Ekpo (2015) found the weights of HOs (asphaltenes) precipitated from a Nigerian crude oil using binary mixtures of n-pentane/n-hexane and nheptane/n-octane. Whereas, Tobrise et al. (2016) evaluated the precipitation of HOs (asphaltenes) from crude oil using binary mixtures of low molecular and higher molecular weight n-alkanes, which include pentane, octane, dodecane, and hexadecane.

The aim of this work is to investigate the effects of mixing two n-alkane solvents (n-hexane $\left(\mathrm{C}_{6}\right)$, ndecane $\left(\mathrm{C}_{10}\right)$, n-tetradecane $\left(\mathrm{C}_{14}\right)$, and n-hexadecane $\left(\mathrm{C}_{16}\right)$ ) on the quantity of HOs precipitated from a Nigerian crude oil.

\section{Experimental}

Sample: Crude oil sample was collected from a major operative in Nigeria. The oil sample was distilled to about $240^{\circ} \mathrm{C}$ and the residue was used for the experiment.

Chemicals: The organic solvents used include analar grade n-hexane (BDH VWR Analytical, USA); n- 
hexadecane (Alfa Aesar, Germany). While, analar grades of n-decane, n-tetradecane were purchased from Sigma Aldrich (United Kingdom).

Methods: A binary mixture of $\mathrm{n}$-alkane solvents $(20$ $\mathrm{mL}$ ) at different ratios (Table 1) was added to about $1.0 \mathrm{~g}$ of oil each in an Erlenmeyer flask. The mixtures were agitated for 30 mins. using mechanical shaker (Staut flask shaker, UK) and settle down for 48hours. Thereafter, the solution was filtered using a vacuum pump system (Leybold-Heraeus pump, UK) and a $0.45 \mu \mathrm{m}$ pore size membrane filter. The flask and the filter were thoroughly rinsed with small volumes of the corresponding solvents mixture to eliminate the residual oil. This was followed by drying in the resultant membrane filter over 2 hours. The weight of precipitated HOs was determined by:

$$
\text { Weight } \%=\frac{\text { weight of } \mathrm{HO} \text { precipitate in } \mathrm{mg} / \mathrm{L}}{\text { weight of residuein } \mathrm{mg} / \mathrm{L}} \times \frac{100}{1}
$$

The ratios $(v / v)$ for the binary mixture of $n$-alkane solvents employed for the analysis is presented in Table 1.

Table 1: Solvent and volume ratios of the binary mixtures of $n$ alkane solvents.

\begin{tabular}{lcccccc}
\hline $\begin{array}{l}\text { Solvent } \\
\text { ratio }\end{array}$ & $0: 1$ & $1: 2$ & $1: 1$ & $2: 1$ & $1: 0$ & $\mathrm{C}_{\mathrm{X}}: \mathrm{C}_{\mathrm{Y}}$ \\
\hline $\begin{array}{l}\text { Volume } \\
\text { ratio in } \\
\mathrm{ml}(\mathrm{v} / \mathrm{v})\end{array}$ & 0 & 6.7 & 10 & 13.3 & 20 & $\mathrm{C}_{\mathrm{X}}$ \\
\cline { 2 - 7 } & 20 & 13.3 & 10 & 6.7 & 0 & $\mathrm{C}_{\mathrm{Y}}$ \\
\hline
\end{tabular}

Where, $\mathrm{C}_{\mathrm{X}}$ and $\mathrm{C}_{\mathrm{Y}}$ indicate the carbon numbers of the n-alkanes solvents used. Moreover, the binary solvent precipitation experiments were each carried out in three replicates according to the method described by Kokal et al., (1992) and Eduardo et al., (2004).

\section{RESULTS AND DISCUSSION}

The result from the precipitation experiments using binary n-alkane solvents $\mathrm{C}_{6}: \mathrm{C}_{10}$ is presented in Figure 1.

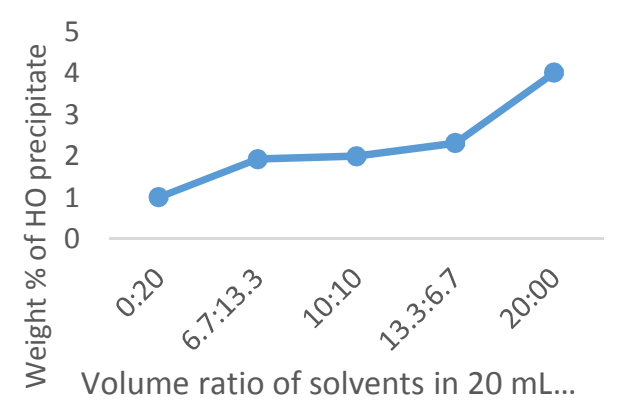

Fig 1: Weight $\%$ of HOs precipitate against volume (v/v) ratios of $\mathrm{n}-\mathrm{C}_{6}$ and $\mathrm{n}-\mathrm{C}_{10}$ binary mixtures in $20 \mathrm{~mL}$ total solvent per gram of oil.

In Figure 1, it was observed that an abrupt decrease of 54\% weight of HOs precipitated from 1:0 volume ratio of $\mathrm{C}_{6}: \mathrm{C}_{10}$ to $2: 1$ volume ratio of $\mathrm{C}_{6}: \mathrm{C}_{10}$. This may partly be due to phase changes due to the addition of small percentage volume of n-decane to $\mathrm{n}$-hexane in the binary mixture. Further increase in the addition of $\mathrm{C}_{10}$ to $\mathrm{C}_{6}$ resulted in a steady decrease of $12 \%$ of the weight of HOs precipitated from 2:1 point of $\mathrm{C}_{6}: \mathrm{C}_{10}$. Another sharp drop of about $34 \%$ of HOs precipitated was observed from 1:2 volume ratio of $\mathrm{C}_{6}$ : $\mathrm{C}_{10}$. This trend confirms the observation made by Tobrise et al. 2016 on single solvent precipitation of HOs, which shows that for an increase in carbon number from $\mathrm{C}_{6}$ to $\mathrm{C}_{10}$, the solubility for $\mathrm{HOs}$ increases resulting in a decrease in the weight percent of $\mathrm{HO}$ precipitated as. In addition, this trend supports the observation made by other research works on the precipitation of HOs from crude oil using individual n-alkane solvents by Eduardo et al., 2004; Mansoori et al., 2007; Chukwu et al., 2011; Saraji et al., 2013; Udourioh et al., 2014; Anuchi; Chukwu 2017. The result from this is that the quantity of HOs precipitated by a combination of two n-alkanes will depend on the volume ratios in which they are combined. At 1:2 and 2:1 volume ratio points, same phase transition was observed which could be due to the precipitation of some species from the liquid phase.

The result from the precipitation experiments using binary n-alkane solvents $\mathrm{C}_{6}: \mathrm{C}_{16}$ is presented in Figure 2. 


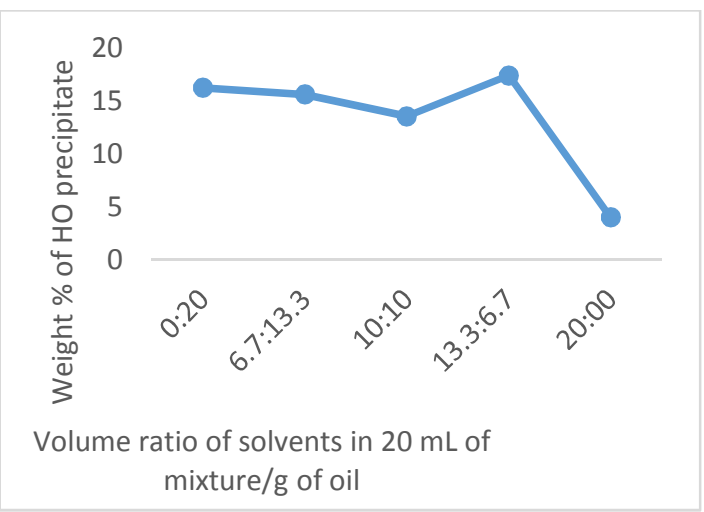

Fig 2: Weight $\%$ of $\mathrm{HO}$ precipitate against volume (v/v) ratios of $\mathrm{n}-\mathrm{C}_{6}$ and $\mathrm{n}-\mathrm{C}_{16}$ binary mixtures in $20 \mathrm{~mL}$ total solvent per gram of oil

Figure 2 shows the initial slow decrease in weight $\%$ of HOs precipitated due to the addition and increase in percentage volume of $\mathrm{C}_{6}$ to $\mathrm{C}_{16}$ from $0: 1$ point. From $1: 2$ ratios $\left(25 \%\right.$ of $\mathrm{C} 6+75 \%$ of $\left.\mathrm{C}_{16}\right)$ point to $1: 1$ ratio $\left(50 \%\right.$ of $\mathrm{C}_{6}+50 \%$ of $\left.\mathrm{C}_{16}\right)$ the decrease was faster. As the increase in volume percent of $\mathrm{C} 6$ continued to $2: 1$ ratio $\left(75 \%\right.$ of $\mathrm{C}_{6}+25 \%$ of $\mathrm{C}_{16}$ ), it resulted in sharp increase in weight $\%$ of $\mathrm{HOs}$ precipitated. Further, increase in the volume of $\mathrm{C}_{6}$ in the mixture at 1:0 ratio of $\mathrm{C}_{6}: \mathrm{C}_{16}$ (i.e $100 \%$ of $\mathrm{C}_{6}$ ) resulted in a very sharp decrease in weight $\%$ of $\mathrm{HOs}$ precipitated. Phase changes in HOs were clearly observed in this trend. At 1:1 volume ratio point, there was a phase transition which may be explained by the precipitation of some $\mathrm{HO}$ species from the liquid phase. At 2:1 volume ratio point, there was another phase transition which may be that some precipitated species re-dissolved in the solvent mixture.

The result from the precipitation experiments using binary n-alkane solvents $\mathrm{C}_{10}: \mathrm{C}_{14}$ is presented in Figure 3.

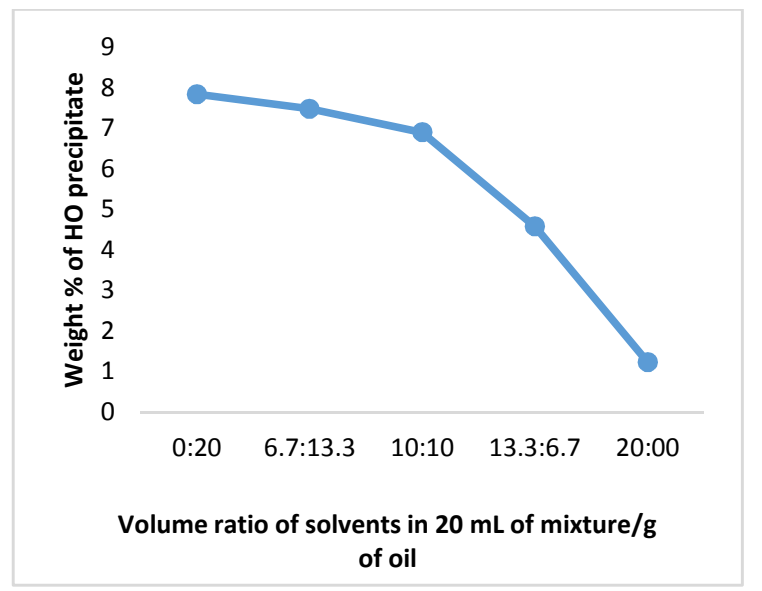

Fig 3: Weight $\%$ of $\mathrm{HO}$ precipitate against (v/v) ratios of $n-\mathrm{C}_{10}$ and $\mathrm{n}-\mathrm{C}_{14}$ binary mixtures in $20 \mathrm{~mL}$ total solvent per gram of oil.

In Figure 3, it was clearly observed that an increase in volume percent of $\mathrm{C}_{10}$ in the binary solvent mixture $\mathrm{C}_{10}$ and $\mathrm{C}_{14}$, decreases the weight $\%$ of HOs precipitated steadily from $0: 1 \quad \mathrm{C}_{10}: \mathrm{C}_{14}$. Further increment in volume percent of $\mathrm{C}_{10}$ to $100 \%$ pure $\mathrm{C}_{10}$ $\left(1: 0\right.$ ratio of $\left.\mathrm{C}_{10}: \mathrm{C}_{14}\right)$, there was a very sharp drop in weight $\%$ of HOs precipitated.

The result from the precipitation experiments using binary n-alkane solvents $\mathrm{C} 10$ : $\mathrm{C} 16$ is presented in Figure 4.

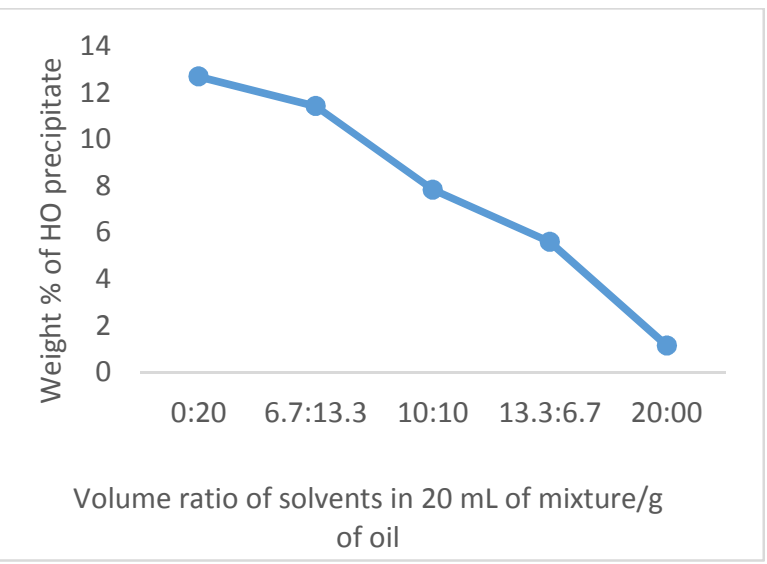

Fig 4: Weight $\%$ of $\mathrm{HO}$ precipitate against volume (v/v) ratios of $\mathrm{n}-\mathrm{C}_{10}$ and $\mathrm{n}-\mathrm{C}_{16}$ binary mixtures in $20 \mathrm{ml}$ total solvent per gram of oil.

The Figure 4 shows that the increase in volume percent of $\mathrm{C}_{10}$ compared to $\mathrm{C}_{16}$ in the binary mixture causes a corresponding decrease in the weight $\%$ of HOs precipitated. This is related to the single nalkane precipitation curve observed by Tobrise et al. 2016. While the result from the precipitation experiments using binary n-alkane solvents $\mathrm{C}_{14}: \mathrm{C}_{16}$ is presented in Figure 5.

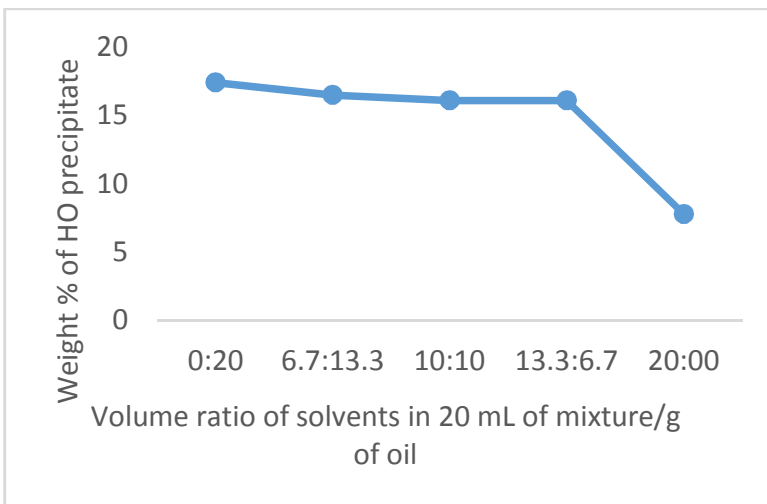

Fig 5: Weight \% of $\mathrm{HO}$ precipitate against volume (v/v) ratios of $\mathrm{n}-\mathrm{C}_{14}$ and $\mathrm{n}-\mathrm{C}_{16}$ binary mixtures in $20 \mathrm{ml}$ total solvent per gram of oil. 
It was clearly observed (Figure 5) that the weight \% of HOs decrease slowly as the volume percent of $\mathrm{C}_{14}$ in $\mathrm{C}_{14}: \mathrm{C}_{16}$ mixture increases to $75 \%\left(0: 1\right.$ ratio of $\mathrm{C}_{14}$ : $\mathrm{C}_{16}$ to $2: 1$ ratio of $\mathrm{C}_{14}: \mathrm{C}_{16}$ ). Further increase in volume percent of $\mathrm{C}_{14}$ to $100 \%$, resulted in a phase change with a transition point followed by a very sharp decrease in weight $\%$ of $\mathrm{HOs}$ precipitated from 2:1 ratio of $\mathrm{C}_{14}: \mathrm{C}_{16}$ to 1:0 ratio of $\mathrm{C}_{14}: \mathrm{C}_{16}$.

Conclusion: Precipitation of HOs from the Nigerian crude oil sample using binary mixtures of n-alkane solvents shows a three-stage phase transition: solidliquid, liquid-solid and solid-liquid in $\mathrm{C}_{6}: \mathrm{C}_{16}$ at different volume ratios of the mixtures. Some of the HOs are soluble in the n-alkane diluted oil; using the single solvent of $\mathrm{C}_{6} \mathrm{n}$-alkane they appear in the liquid phase. As $\mathrm{C}_{16} \mathrm{n}$-alkane solvent is added, part of the dissolved HOs in the liquid phase probably begins to form colloids which lead to agglomeration and precipitation. This brings about the increase in the quantity of precipitate. In the oilfield, compositional changes of petroleum fluids result in different contributions to the solubility or insolubility of heavy HOs in the oil. At critical values for the combination of n-alkane precipitants in crude oils containing all the precipitant n-alkane solvents $\mathrm{C}_{1}$ to $\mathrm{C}_{18}$, HOs will precipitate. The laboratory experiment of binary mixtures of $n$-alkanes gives a better explanation of the precipitation and deposition HOs in the oilfield than in single solvent precipitation experiments

\section{REFERENCES}

Achugasim, O; Ekpo, I.E. (2015). Precipitation of Heavy Organics (Asphaltenes $\}$ from Crude Oil Residue Using Binary Mixtures of n-Alkanes. Advances in Chemical Engineering and Science. (5): 96-101.

Anuchi, S.O; Chukwu, U.J. (2017). Investigation of Heavy Organics Precipitation from Nigerian Crude Oil Residue Using Single n-Alkane Solvents. IOSR Journal of Applied Chemistry. 10(4): 22-25.

Chukwu, O.C; Ofodile, S.E; Okoye, I.P. (2011). The Effect of Different Solvent Polarity on the Precipitation of Heavy Organics from a crude oil deposit in the Niger Delta. Scientia Africana. 10(2): 9-15.
Eduardo, B.G; Carlos, L.G; Alejandro, G.V; Jianzhong, W.U. (2004). Asphaltene Precipitation in Crude Oils: Theory and Experiments. Journal of AIChE. 50(10): 25522570 .

Escobedo, J; Mansoori, G.A. (2010). Heavy-organic particle deposition from petroleum fluid flow in oil wells and pipelines. Journal of Petroleum Science. 7: 502-508.

Kokal, S.L; Najman, J; Sayeh, S.G; George, A.E. (1992). Measurement and Correlation of Asphaltene Precipitation from Heavy Oils by Gas Injection. J. Can. Petrol. Technol., 31,24.

Mansoori, G.A.; Vazquez, D; Shariaty-Niassar, M. (2007). The polydispersity of heavy organics in crude oils and their role in oil well fouling, J. Petrol. Sci. and Eng'g, September. 58 (4): 375390.

Salimi, F; Salimi, J; Abdollahifar, M. (2016). Investigation of asphaltene deposition under dynamic flow conditions. Pet. Sci. 13: 340-346.

Saraji, S; Goual, L; Piri, M. (2013). Dynamic Adsorption of Asphaltenes on Quartz and Calcite Packs in the Presence of Brine Films. Colloids and Surfaces A: Physicochem. Eng. Aspects. 434: 260-267.

Tobrise, O.O; Ofodile, S.E; Osu, C; Achugasim, O. (2016). Comparative Evaluation of Asphaltene Precipitation from Nigerian Crude Oil Residue Using Intermediate and Long Chain Single and Binary N-Alkane Solvent Mixtures. IOSR Journal of Applied Chemistry. 9 (5): 82-86.

Udourioh, G; Ibezim-Ezeani, M. I; Ofodile, S.E. (2014). Comparative Investigation of Heavy Organics Precipitation from Crude Oil Using Binary Mixtures and Single n-Alkane Organic Solvents. Journal of Petroleum and Gas Exploration Research. 4(4): 53-59. 